NBER WORKING PAPER SERIES

\title{
DO CONSUMERS EXPLOIT PRECOMMITMENT OPPORTUNITIES? EVIDENCE FROM NATURAL EXPERIMENTS INVOLVING LIQUOR CONSUMPTION
}

\author{
B. Douglas Bernheim \\ Jonathan Meer \\ Neva K. Novarro \\ Working Paper 17762 \\ http://www.nber.org/papers/w17762 \\ NATIONAL BUREAU OF ECONOMIC RESEARCH \\ 1050 Massachusetts Avenue \\ Cambridge, MA 02138 \\ January 2012
}

We are grateful to Jennifer Doleac, Mark Hoekstra, Michael Lovenheim, Harvey Rosen, Jeremy West, and William Gui Woolston for valuable comments, to Michael Lovenheim and Mark Stehr for useful data, to Jillian Carr, Mario Garza, Mustafa Karakaplan, Analisa Packham, Xander Slaski, and Zhihao Zhang for able research assistance, and to numerous state alcohol board agents, law librarians, and legislative assistants for clarifying important data issues. The views expressed herein are those of the authors and do not necessarily reflect the views of the National Bureau of Economic Research.

NBER working papers are circulated for discussion and comment purposes. They have not been peerreviewed or been subject to the review by the NBER Board of Directors that accompanies official NBER publications.

(C) 2012 by B. Douglas Bernheim, Jonathan Meer, and Neva K. Novarro. All rights reserved. Short sections of text, not to exceed two paragraphs, may be quoted without explicit permission provided that full credit, including $(\mathcal{C}$ notice, is given to the source. 
Do Consumers Exploit Precommitment Opportunities? Evidence from Natural Experiments Involving Liquor Consumption

B. Douglas Bernheim, Jonathan Meer, and Neva K. Novarro

NBER Working Paper No. 17762

January 2012, Revised October 2015

JEL No. D03,D12,H31,I10

\begin{abstract}
$\underline{\text { ABSTRACT }}$
This paper provides evidence concerning the extent to which consumers of liquor employ commitment devices. One widely recommended commitment strategy is to regulate alcohol consumption by deliberately manipulating availability. The paper assesses the prevalence of the "availability strategy" by evaluating the effects of policies that would influence its effectiveness - specifically, changes in allowable Sunday sales hours. It finds that consumers increase their liquor consumption in response to extended Sunday on-premises sales hours, but not in response to extended off-premises sales hours. The latter finding is inconsistent with widespread use of the availability strategy.
\end{abstract}

B. Douglas Bernheim

Department of Economics

Stanford University

Stanford, CA 94305-6072

and NBER

bernheim@stanford.edu

Jonathan Meer

Department of Economics

TAMU 4228

College Station, TX 77843

and NBER

jmeer@econmail.tamu.edu
Neva K. Novarro

Department of Economics

425 N College Ave.

Claremont, CA 91711

nnovarro@gmail.com 


\section{Introduction}

Over the last twenty years, the concept of time inconsistency has emerged as a central theme in behavioral economics, one that has begun to influence thinking concerning public policy. ${ }^{1}$ As is well-known, any consumer sufficiently self-aware ("sophisticated") to notice her timeinconsistent tendencies will manifest a demand for commitment technologies. It is often assumed that consumers will acquire such self-awareness in the context of frequently repeated activities for which they consistently fail to follow through on prior intentions. Yet oddly, there is surprisingly little evidence that people actually value and exploit commitment opportunities. Most of the pertinent literature echoes this evaluation. For example, Gine, Karlan, and Zinman (2010) write that "there is little field evidence on the demand for or effectiveness of such commitment devices” (see also the excellent surveys by Bryan et al., 2010, and DellaVigna, 2009). A collection of relatively recent papers has begun to fill that gap: see in particular Ariely and Wertenbroch (2002) on homework assignments, Ashraf, Karlan, and Yin (2006) and Beshears et al. (2015) on commitment savings devices, and Kaur, Kramer, and Mullainathan (2015) on incentive schemes. Still, nagging doubts persist, partly because the evidence is limited to particular decision contexts, and partly because much of it is equivocal. For example, the demand for commitment savings products in developing countries is potentially attributable to other-control (i.e., family and friends) rather than to self-control; see, e.g., Dupas and Robinson (2013). Skeptics continue to wonder why, if sophisticated time inconsistency is so prevalent, the market and regulators provide so few commitment devices, and unambiguous examples of costly commitments in the field are so difficult to find. Indeed, some suggest that the fewness of the obvious exceptions proves the rule.

The consumption of addictive substances is often offered as a leading example of time inconsistency. Becker and Murphy (1988) have shown that a consumer with time-consistent preferences could exhibit many of the choice patterns associated with such substances. However, unlike behavioral theories of addiction that posit sophisticated time inconsistency based on quasi-hyperbolic discounting (Gruber and Koszegi, 2001), cue-triggered visceral modes (Bernheim and Rangel, 2004), or temptation preferences (Gul and Pesendorfer, 2007), the Becker-Murphy

\footnotetext{
${ }^{1}$ Examples of policy applications include Laibson (1997, 1998), Laibson, Repetto, and Tobacman (1998), Krussell, Kuruscu, and Smith (2000), Diamond and Koszegi (2003), Thaler and Benartzi (2004), Bernheim and Rangel (2004), Amador, Werning, and Angeletos (2006), Fang and Silverman (2009), Banerjee and Mullainathan (2010), Bernheim, Ray, and Yeltekin (2013), and many others.
} 
model does not imply a demand for commitment. Despite the centrality of this implication, evidence that users of addictive substances actually value commitment opportunities is almost entirely limited to anecdotes. An important recent exception is Gine, Karlan, and Zinman (2010), who study the use of a commitment device for smoking cessation, but the general lessons to be drawn from their experiment are unclear. ${ }^{2}$ Without more systematic and extensive evidence, it is impossible to know whether the anecdotes pertain to commonplace or exceptional modes of behavior.

Some evidence from clinical practice actually casts a degree of doubt on the hypothesis that addicts value commitment opportunities. For example, alcoholics can commit to sobriety by taking disulfiram, a drug that produces an unpleasant reaction to alcohol. However, only supervised disulfiram administration is generally recognized as effective; compliance is poor among patients who are given the drug to take on their own (see, e.g., Hughes and Cook, 1997, and Anton, 2001). Of course, an alcoholic who uses disulfiram runs the risk that he will give in to cravings and experience an extremely unpleasant reaction. Poor compliance may be attributable to this risk rather than to the absence of a demand for commitment more generally.

A simple method for exercising self-control is to limit the availability of a problematic good by not maintaining an easily accessed supply. For example, dieters are counseled against keeping fattening foods at home, while smokers and alcoholics who wish to quit or at least control their habits are often given similar advice. The National Institute on Alcohol Abuse and Alcoholism (a division of the National Institutes of Health) maintains a website called "Rethinking Drinking,” on which it offers “Tips to Try” for those who have not decided to give up alcohol entirely but want to cut down; see NIAAA (2012). It recommends that "[i]f drinking at home is a problem, keep little or no alcohol there.” This recommendation is echoed in many other selfhelp resources.

We will refer to this self-control technique as the availability strategy. Notice that it involves a partial commitment: while it does not prevent an individual from obtaining the good in

\footnotetext{
${ }^{2}$ Subjects were offered the opportunity to post a bond, the principle of which was forfeited to a charity if they failed a urine test after six months. The take-up rate was 11 percent. One interpretation of this figure is that it reflects a limited demand for commitment devices (or at least for this particular commitment device), especially inasmuch as generosity or a desire to signal generosity toward the charity may have artificially inflated the take-up rate. (In this regard, it is worth noting that two-thirds of those who participated continued to smoke.) An alternative interpretation is that 11 percent is high in light of the contract's novelty, and indicates a strong latent demand for commitment devices. In a more recent study of smoking cessation (Halpern et al., 2015), the take-up rate for a related commitment device was similar (13.7\%).
} 
question, it restricts future opportunities in a way that makes the targeted behavior less convenient. When enumerating popular commitment devices, economists regularly cite the use of the availability strategy to control alcohol consumption. According to Schelling (1988), the strategy is to “[r]emove the mischievous resources: don’t keep liquor, or sleeping pills, in the house.” Likewise, Bryan, Karlan, and Nelson (2010) describe a handful of techniques to illustrate "ad hoc commitment devices,” which includes “not keeping alcohol in the house.”

In this paper, we look for evidence that consumers actually employ the availability strategy to control their liquor consumption. We exploit a collection of state-level policy changes that altered the hours during which consumers can purchase liquor on Sundays (so-called "blue laws”). Someone who attempts to control liquor consumption by keeping no liquor at home will have greater success (at least on Sundays) in a regime with strict blue laws. Thus, under the hypothesis that the availability strategy is prevalent, a relaxation of blue laws should lead to a noticeable increase in liquor consumption. Of course, the same implication follows even if consumers have no interest in making commitments: assuming (plausibly) that liquor is complementary to restaurant meals and socializing at bars, then those who like to dine out and/or socialize on Sundays will consume less liquor in a regime with stringent blue laws. Thus, the mere fact that blue laws reduce liquor consumption - a proposition that already has some support in the literature (see Section 2) - cannot discriminate between the hypotheses of interest. A more discerning test is needed.

A critical feature of our analysis is that it distinguishes between restrictions on offpremise liquor sales (through liquor and package stores) and on-premise sales (in restaurants and bars). For a practitioner of the availability strategy, both types of restrictions make the acquisition of alcohol significantly more difficult when none is kept at home; hence both should reduce liquor consumption. In contrast, time-consistent and naively time-inconsistent consumers should respond to off-premise restrictions by carrying “inventories.” Sunday off-premise sales restrictions could affect liquor consumption among such consumers only if they are forgetful, the costs of carrying inventories are large, or (in the case of naive time inconsistency) they find themselves without inventories due to procrastination. Thus, models of time-consistent or naively time-inconsistent consumption can easily account for the absence of a relationship between liquor consumption and off-premise sales restrictions (indeed, we take this to be the most natural implication of time consistency). These same models have different implications for on-premise 
sales restrictions because alcohol in bars and restaurants is not storable (consumers cannot hold inventories), and consumers are not completely indifferent with respect to going out on different days of the week.

We investigate these issues by examining the effects on annual state-wide liquor purchases of changes in state laws defining allowable Sunday hours for liquor sales. We focus on liquor rather than wine or beer for two reasons. First, sales restrictions are generally simpler and easier to code for liquor than for beer and wine. For instance, many states have historically carved out exemptions for certain types of wine and beer based on alcohol content. Second, there is evidence that the self-control problems commonly associated with alcohol consumption are most prevalent for liquor (see, for example, Kerr et al., 2002, or Roizen et al. 1999). We examine 32 changes in allowable off-premise hours and 46 changes in allowable on-premise hours occurring between 1970 and 2007; in 22 of these cases, states changed both limits during the same year. We estimate panel regressions with state fixed effects (to control for unobserved differences in attitudes toward alcohol that may affect both regulations and consumption) and year effects (to control for general trends in liquor consumption over time). Thus, we identify the effects of restrictions on allowable Sunday sales hours by, in effect, comparing the changes over time in liquor purchases for states that modified their regulations to the changes for states that did not. We address some threats to our identification strategy below.

Our central finding is that liquor consumption increases along with allowable on-premise Sunday sales hours, but there is no evidence that it is affected by off-premise Sunday sales hours. These findings are robust with respect to a wide variety of specifications, including ones that control for pre-existing trends and concurrent changes in related restrictions. Thus, to our considerable surprise, we find no indication that the availability strategy plays a meaningful role in aggregate liquor consumption. Instead, the observed pattern coincides with our prediction for time-consistent consumers who have good memories and low costs of carrying inventories, as well as for naive time-inconsistent consumers who, in addition, do not regularly find themselves without inventories due to unintentional procrastination of shopping. Naturally, the possibility remains that liquor purchasers are time-inconsistent and sophisticated, but that they favor some other technique for exercising self-control. For instance, Bernheim, Ray, and Yeltekin (2015) demonstrate that a sophisticated time-inconsistent consumer may avoid external commitments because they undermine internal self-control strategies. 
In addition to shedding light on the demand for commitment devices, our analysis also has direct implications for tax policy. Over the last few decades, many states have repealed or relaxed blue laws in an attempt to increase tax revenues. The efficacy of these measures is controversial. For example, an article in the New York Times cited projections that permitting Sunday sales would increase tax revenues in Georgia, but also referenced unnamed analysts who “are less certain that [this step] will bring in much new money because drinkers are likely simply to shift the days they buy alcohol” (Severson, 2011). Our analysis informs that debate by showing that relaxing restrictions for on-premise sales is likely to increase revenue, but doing so for off-premise sales is not.

\section{Relation to the Existing Literature on the Effects of Blue Laws}

There is a small but growing literature concerning the effects of blue laws on the consumption of alcohol and alcohol-related behaviors. However, that literature has not explored the implications of those effects regarding time-inconsistency and the demand for commitment technologies, or estimated the effects in a way that permits one to draw those implications.

Several studies have estimated the impact of blue laws on alcohol consumption. Ornstein and Hanssens (1985) evaluate the effects of several alcohol control measures using a state-level cross-section. They include a dummy variable indicating whether a state allows off-premise Sunday sales and find a positive and statistically significant relationship for beer but an implausible negative (and statistically significant) relationship for liquor. Stehr (2007) uses panel data to estimate the effects of alcohol taxes and Sunday restrictions on off-premise alcohol sales; ${ }^{3}$ he finds that liquor consumption increases by 3 to 7 percent when a Sunday off-premise ban is repealed. Carpenter and Eisenberg (2010) provide cross-sectional evidence for Canadian provinces, and study changes in the drinking habits of Ontario residents after that province repealed its Sunday ban on off-premise sales in 1997. Based on survey data, they find an increase in drinking on Sundays coupled with a decline on Saturdays, and "no evidence that these policies affected overall population drinking rates.”

Two considerations prevent one from drawing implications concerning the demand for commitment devices from the aforementioned studies. First, cross-sectional evidence on the effects of blue laws (e.g., Ornstein and Hanssen, 1985, and much of Carpenter and Eisenberg,

\footnotetext{
${ }^{3}$ Stehr's paper does not explicitly mention whether the changes he examines pertain to off-premise or on-premise sales. He clarified this issue for us through a personal communication.
} 
2010) is suspect due to the likelihood that unobserved differences in attitudes toward alcohol affect both regulations and consumption. Second, none of these studies explicitly controls for restrictions pertaining to on-premise alcohol sales. In our sample, the correlation between allowable on-premise and off-premise Sunday sales hours is 0.57 , and states changed both limits in the same year 22 times, which represents $69 \%$ of the changes in allowable off-premise hours, and $48 \%$ of the changes in allowable on-premise hours. Thus, the effects measured by the aforementioned studies (whether in cross-sections or panel data) likely reflect the blended impact of offpremise and on-premise restrictions. While this consideration is not especially problematic for their purposes, it is fatal for ours (because we are concerned with the differential impact of offpremise and on-premise restrictions). The one exception is Carpenter and Eisenberg's analysis of Ontario’s 1997 liberalization; as far as we can determine, Ontario did not alter on-premise restrictions on alcohol sales at the same time. However, that evidence is limited to a single policy change; consequently, all statements concerning statistical significance presuppose the absence of any common unobserved shocks to alcohol consumption across Ontario residents.

We also depart from the aforementioned literature by studying the effects of allowable hours rather than outright bans. Information on bans is far more readily available than data on allowable hours. We undertook the time-consuming process of collecting the latter information because it permits us to employ richer characterizations of each state's policies, and because it enables us to study the effects of a much larger set of legislative events.

In principle, one can also draw inferences concerning the effects of blue laws on alcohol consumption indirectly from studies that examine alcohol-related activity - specifically, traffic accidents and crime. McMillan and Lapham (2006) found that repealing the ban on off-premise Sunday alcohol sales in New Mexico led to a $29 \%$ increase in alcohol-related traffic accidents and a 42\% increase in alcohol-related traffic fatalities. Similarly, Ligon and Thyer (1993) found that a Sunday sales ban on alcohol reduced the incidence of DUIs. Smith (1990) reports on a handful of studies concerning alcohol policy changes in Australia; generally, he finds a positive relationship between increased Sunday alcohol sales and traffic accidents. Olsson and Wikstrom (1982) note that alcohol sales fell by 8\% during an experimental period in 1981 when Swedish liquor stores were closed on Saturdays, with accompanying declines in domestic disturbances and arrests for drunkenness; however, they are careful to point out that causality is unclear because the experiment was nationwide. Other recent studies have found much more limited ef- 
fects. Stehr (2010) examines changes in Sunday off-premise sales bans in a number of states and finds an increase in traffic fatalities only for New Mexico. Using similar data, Lovenheim and Steefel (2010) conclude that "blue laws have little effect on fatal accidents.” Finally, a recent paper by Heaton (2012) showed that crime increased somewhat along with the phased introduction of Sunday package liquor sales in Virginia. Like the studies of alcohol consumption mentioned above, most of these analyses shed limited light on the questions motivating our investigation because they make no explicit attempt to differentiate between the effects of on-premise and off-premise sales, and/or concern single policy changes. One must also exercise caution in drawing conclusions about alcohol consumption from alcohol-related activity; for example, the ab-

sence of a statistically significant effect on traffic accidents or crime would not necessarily imply the absence of a statistically significant effect on consumption. Moreover, for changes in recorded alcohol-related crimes, associated changes in reporting and/or enforcement may create confounds. For example, an officer may be more likely to record the presence of alcohol when writing up a Sunday crime if a ban is in place, and police departments may react to the relaxation of sales restrictions by setting more traps for drunk drivers.

The current paper is also related to recent work by Hinnosaar (2012), who estimates the effect of a ban on Sunday beer sales indirectly, rather than from studying actual policy changes. Using scanner data on beer purchases, she derives an estimate of the fraction of consumers who have time-inconsistent preferences, and then uses that model to simulate the effects of a Sunday ban under the assumption that those consumers would employ the availability strategy. Her work is complementary to ours, in that we examine actual policy changes and determine whether behavioral responses are consistent with commitment behavior.

\section{Theoretical Considerations}

\subsection{A simple model of off-premises alcohol consumption}

A simple theoretical model helps to illuminate the circumstances in which people may attempt to exercise self-control over off-premises alcohol consumption by limiting readily available supplies. For simplicity, the model has only three time periods, $t=0,1,2$. Decisions unfold as follows.

At time 0, the consumer has a convenient opportunity to purchase one unit of alcohol. By “convenient," we mean that he shops at time 0 for other reasons, so that the incremental cost of 
buying alcohol is limited to its price, $C$. For simplicity, no consumption occurs at time 0 , but any alcohol purchases are costlessly storable.

At time 1, the consumer decides whether or not to drink a unit of alcohol. The immediate utility benefit of doing so is $B$. (For simplicity, we express all utility benefits and penalties, including $B$, as dollar equivalents.) If he has purchased and stored alcohol at time 0 , consumption involves no other immediate costs. If he has no supply at home, he can make a separate trip to buy some at the price $C$, but also incurs an immediate utility penalty, $T$, as a result of the inconvenience.

Time 2 represents the future, during which various costs are incurred. We will use $H$ to denote the future penalty associated with consuming alcohol, including for example its adverse effect on health. The future penalty associated with purchasing alcohol is, of course, $C$, its price. We characterize this as a future penalty rather than a current one because spending money on alcohol requires an offsetting reduction in other spending, but not immediately.

In addition, if the consumer purchased alcohol at time 0 and did not drink it at time 1 , he will receive some additional benefit from owning alcohol at time 2. Instead of deriving that value in the context of a full dynamic programming model, we simplify by assuming that the consumer must hold a unit of alcohol at the end of this period. Consequently, if he does not carry stock into period 2, he must purchase it at the cost $C$. He does so when shopping for other reasons, so that the inconvenience cost $T$ is avoided. Alternatively, one could assume that the consumer can sell any stock he owns as of time 2; the results are the same.

Following much of the literature on time inconsistency (for example, Laibson, 1997, 1998, and O'Donoghue and Rabin, 1999), we assume the consumer has quasihyperbolic preferences: he discounts utility $t$ periods in the future by the factor $\beta \delta^{t}$, where $\beta, \delta \in[0,1]$. For our purposes, $\beta$ is the parameter of interest because it governs the degree of time inconsistency. For notational simplicity, we will assume $\delta=1$. Inasmuch as we think of periods 0 and 1 as single days, this is a reasonable assumption. It is also without loss of generality because we can treat the parameters $B, C, T$, and $H$ as already incorporating $\delta$-discounting.

Accordingly, the consumer always maximizes the difference between immediate benefits and costs, plus a factor $\beta \in[0,1]$ times the difference between future benefits and costs. Note that $\beta$ matters only at time 1 : at time 0 , he makes a decision but faces no immediate consequences, while at time 2 , he makes no decision. We assume that the value of $\beta$ applicable at 
time 1 is realized at the outset of that period, and that its distribution is governed by $F$, a CDF

with support $[\underline{\beta}, \bar{\beta}]$. We treat $\beta$ as random on the grounds that the severity of self-control problems depends on environmental cues that the consumer may or may not encounter, as in Bernheim and Rangel [2004].

We classify the consumer as potentially time-inconsistent with respect to alcohol if his use of alcohol at time 1 could depend on the timing of his decision (i.e., whether he makes the choice at time 0 or time 1 ). Conversely, we classify him as time-consistent with respect to alcohol if his use of alcohol at time 1 definitely does not depend on the timing of his decision. Note that $\beta=1$ is a sufficient condition for time-consistency with respect to alcohol, but it is not a necessary condition. We will assume for the moment that the consumer is potentially timeinconsistent with respect to alcohol, which requires $B-C-H<0$, so that as of time 0 he wishes to avoid drinking at time 1 , and $B-\underline{\beta}(C+H)>0$, so that as of time 1 he may wish to drink at time 1.

\subsection{The effect of a Sunday sales ban on off-premises alcohol sales}

Period 1 is the point in time at which sales restrictions on alcohol may apply - in other words, it represents "Sunday." At the outset, we will assume that no such restrictions are in place, and examine the consumer's decisions.

If the consumer holds a unit of alcohol at time 1 , he will drink it as long as $B \geq$ $\beta(C+H)$. Consequently, assuming he is sophisticated, his expected utility conditional upon purchasing a unit at time 0 , from the perspective of time 0 , is:

$$
U_{P}=\beta\left[F\left(\frac{B}{C+H}\right)(B-C-H)-C\right] .
$$

In contrast, if he does not hold a unit at time 1 , he will purchase one and drink it as long as $B-T \geq \beta(C+H)$. Because he ends up purchasing alcohol at time 2 regardless of whether he consumes at time 1 , his expected utility conditional upon not purchasing a unit at time 0 , from the perspective of time 0 , is:

$$
U_{N P}=\beta\left[F\left(\frac{B-T}{C+H}\right)(B-C-H-T)-C\right] .
$$

A sophisticated consumer controls alcohol consumption by keeping no easily accessible supplies iff $U_{P} \leq U_{N P}$ (resolving indifference in favor of no purchase), or equivalently

$$
1+\frac{T}{C+H-B} \leq F\left(\frac{B}{C+H}\right) / F\left(\frac{B-T}{C+H}\right) \text {. }
$$


Notice that refraining from purchasing alcohol at time 0 reduces total expected purchases from $1+F\left(\frac{B}{C+H}\right)$ to $1+F\left(\frac{B-T}{C+H}\right)$.

Depending on the values of the model's parameters, a sophisticated consumer may or may not choose to maintain a readily available supply. For instance, if $F\left(\frac{B-T}{C+H}\right)=0$ (but $F\left(\frac{B}{C+H}\right)>0$ ), so that the absence of readily available supply definitely deters drinking, we necessarily have $U_{P}<U_{N P}$, which means the consumer buys nothing at time 0 . On the other hand, if $F\left(\frac{B-T}{C+H}\right)=1$ (which implies $F\left(\frac{B}{C+H}\right)=1$ ), the consumer drinks regardless of whether he maintains a supply at home, so $U_{P}>U_{N P}$; in other words, it is optimal to avoid the costs of inconvenience by stocking up in advance.

Now imagine that a law prevents sales of alcohol at time 1 ("Sunday”). Assuming the consumer stocks up at time 0 , his outcome is unchanged: we have $U_{P}^{B}=U_{P}$ (where the superscript $B$ denotes an outcome with a ban). However, if he fails to stock up, he can consume nothing at time 1 , and hence his payoff is simply $U_{N P}^{B}=-\beta C$. Because $B-C-H<0$, we have $U_{P}^{B}<U_{N P}^{B}$, so he is unambiguously better off purchasing nothing at time 0 . Consequently, his overall expected purchases fall to unity, irrespective of the parameters.

According to the preceding analysis, a Sunday ban on liquor sales reduces off-premises purchases for two distinct reasons. First, it increases the effectiveness of the availability strategy conditional upon its use (the "efficacy channel”). To understand why this is the case, notice that $1+F\left(\frac{B-T}{C+H}\right)>1$. Second, as a consequence of this increased effectiveness, a sales ban also enlarges the set of individuals who attempt to employ the availability strategy (the "usage channel”).

There are, of course, special conditions under which a Sunday ban has no effect on aggregate liquor purchases despite consumers' use of the availability strategy. First, without a ban, the availability strategy must be perfectly effective for all those who use it. This requires $F\left(\frac{B-T}{C+H}\right)=0$, so that the individual would not make a special trip to the store to purchase liquor under any circumstances. Second, again without a ban, there must be no "marginal” consumers for whom the net benefits of the availability strategy are not quite sufficient to justify its use. The first condition disables the efficacy channel, while the second disables the usage channel. We regard these conditions as highly unrealistic in light of other considerations. First, alcohol consumption is notoriously difficult to self-regulate, and the clinical literature implies that simple 
self-control strategies are far from perfect (see, e.g., Collins, 1993). Second, it is difficult to imagine a plausible distribution of underlying characteristics for which the alcohol-consuming population would divide between those who use and do not use the availability strategy while leaving no one on the margin.

Critically, our conclusion concerning the effect of a Sunday sales ban hinges on the assumption that the consumer is potentially time-inconsistent with respect to alcohol. For if $B-\underline{\beta}(C+H)<0$, he would purchase no alcohol under any circumstances, and if $B-C-H>$ 0 , he would always stock up on alcohol at time 0 to avoid the consequences of running out. It also hinges on the assumption that the consumer is at least somewhat sophisticated. It is easy to check that that same analysis goes through for a partially sophisticated consumer who incorrectly believes the distribution of $\beta$ to be $\tilde{F}$ rather than $F$, with the exception that $\tilde{F}$ replaces $F$ in expressions governing period 0 decisions; see, for example, O'Donoghue and Rabin (2001), DellaVigna and Malmendier (2004), and Bernheim, Fradkin, and Popov (2015) for formulations of partial naivete. However, a completely naive time-inconsistent consumer would behave just like a time-consistent one in period $0 .{ }^{4}$ Thus, interpreted strictly through the lens of our simple model, the degree to which a ban on Sunday off-premise sales reduces overall alcohol consumption provides a gauge of the extent to which consumers exercise self-control through the availability strategy as a consequence of partially or fully sophisticated time inconsistency.

Stepping outside of our simple model, a Sunday ban could reduce alcohol by timeconsistent or naively time-inconsistent consumers if they face significant inventory-holding costs, typically incur lower inconvenience costs on Sundays than on other days, sometimes inadvertently forget to stock up, or (in the case of naive time inconsistency) periodically find themselves without supplies due to unforeseen procrastination of shopping trips. Thus, strictly speaking, a finding that Sunday sales hours significantly affect liquor consumption would not rule out either time consistency or naivete. However, we question whether these consideration could plausibly account for large effects. For example, the costs of holding inventories appear to be minor; moreover, consumers who regularly drink liquor (and who therefore account for the bulk

\footnotetext{
${ }^{4}$ Technically, a naive time-inconsistent consumer would be indifferent about purchasing alcohol in period 0 . Those who resolve that indifference in favor of no purchase would effectively implement the availability strategy unintentionally, and consequently a Sunday sales ban would reduce their total consumption. That said, if we added some uncertainty with respect to $B$, so that $B>C+H$ in at least some states of nature (however unlikely), the naive consumer would strictly favor stocking up in advance, and a Sunday sales ban would have no effect.
} 
of sales) are likely to learn from experience and develop habits that help them avoid inadvertent depletion of supplies. More importantly, because these considerations would amplify rather than offset the effects of the availability strategy, a finding that liquor consumption is unaffected by Sunday off-premises sales hours would remain inconsistent with the hypothesis that significant numbers of consumers employ that strategy.

\subsection{Some extensions}

Up to this point, we have assumed that a ban on "Sunday" off-premise sales makes alcohol unavailable, or equivalently that it increases the value of $T$ by a large (prohibitive) amount. In fact, consumers may be able to obtain alcohol on Sundays at a higher but non-prohibitive cost by going to a bar or restaurant, in which case a ban effectively increases $T$ by some smaller amount. $^{5}$ Strictly speaking, the effect of a small increase in $T$ on total alcohol consumption is theoretically ambiguous: conditional on refraining from purchasing alcohol at time 0 , consumption declines (because the effective price rises), but more people could end up purchasing alcohol at time 0 (for example, if they know they would otherwise likely incur the higher costs of going to a bar). The latter possibility strikes us as rather perverse: it requires that, on the margin, an increase in inconvenience costs starting from $T$ reduces the attractiveness of the availability strategy, even though that strategy is more attractive when those costs are $T$ rather than zero, ${ }^{6}$ and more attractive when they are $B$ (that is, prohibitive) rather than $T$. Still, in light of this theoretical possibility, we investigate whether the effect of a change in off-premise sales hours differs according to the length of on-premise sales hours as part of our empirical analysis.

So far, we have also treated "Sunday" as a single time period. This would be appropriate if the desire for alcohol remained constant throughout the entire day. A more realistic assumption is that it depends on the consumer's activities and experiences (as discussed in Bernheim and Rangel, 2004), which vary considerably over the course of a day. In a more elaborate model, one could represent Sunday as a series of time periods (such as "hours”), with separate imperfectly correlated realizations of $\beta$ for each. For a consumer using the availability strategy, total

\footnotetext{
${ }^{5}$ As is clear from Table 2, off-premises Sunday sales hours are generally shorter than on-premises hours. In principle, a consumer might also obtain alcohol on Sunday from friends. But anyone attempting to control alcohol consumption through the availability strategy would also have an incentive to encourage their friends not to share alcohol with them on Sundays. For those unable to control access through friends, the availability strategy is likely ineffective to begin with.

${ }^{6}$ When inconvenience costs are zero, the consumer's payoff is the same regardless of whether or not he purchases alcohol at time 0 . Therefore, he will refrain from purchasing at time 0 when the inconvenience costs are $T$ only if the availability strategy delivers a higher payoff with inconvenience costs of $T$ than with inconvenience costs of zero.
} 
alcohol consumption would then depend on the number of periods during which sales are allowed. Accordingly, in our empirical analysis, we focus primarily on the effects of changes in allowable Sunday sales hours, rather than on whether or not a state bans Sunday sales entirely.

\subsection{The effects of a Sunday sales ban on on-premises alcohol sales}

It is important to emphasize that the conclusions highlighted above pertain to offpremises, rather than on-premises, alcohol consumption. To understand why, consider the effects of a change in on-premise sales hours. As a first step, suppose the timing of the individual's trips to bars and restaurants is fixed. An important difference between off-premise and onpremise purchases is that alcohol is storable in the former context but not in the latter. Assuming that alcohol is complementary to restaurant meals and/or social interaction (so that consumption at home is an imperfect substitute), a partial or complete ban on Sunday sales will unambiguously reduce purchases. Next consider how changes in the timing of trips affect this conclusion. A consumer who is time-consistent with respect to alcohol may shift his trips away from Sundays to avoid the ban. This response will mute the reduction in consumption to some degree, but not entirely, unless he is completely indifferent as to timing. A sophisticated time-inconsistent consumer with self-control problems may shift his trips to Sundays to take advantage of the ban (thus exposing himself to cues that could trigger alcohol consumption only when it is not available). That will magnify the reduction in consumption. Finally, a naïve time-inconsistent consumer with self-control problems will not adjust the timing of his trips, because he expects to refrain from consuming. Thus, regardless of the composition of the population, an abbreviation of on-premise Sunday hours should reduce on-premises alcohol purchases.

\subsection{Moving from theory to practice}

Our simple theory assumes that consumers fully reoptimize in response to changes in Sunday alcohol sales restrictions. Yet in practice, even sophisticated consumers may view the incremental impact of marginal changes in Sunday sales hours on overall exposure to temptation as too small to justify reformulating self-control strategies. More generally, the prevalent selfcontrol strategies may evolve slowly as new policies are enacted.

When considering these possibilities, it is important to recall that, according to our model, Sunday off-premises sales restrictions affect alcohol consumption through two separate channels, one involving usage of the availability strategy, the other involving its efficacy. While a failure to reoptimize would neutralize the usage channel, the efficacy channel would remain fully 
operational. In other words, those who chose to employ the availability strategy under the preexisting regime would find this strategy less effective on Sundays under a new regime with longer sales hours. At a minimum, an empirical study of the relation between alcohol consumption and sales hours ought to detect that effect.

A corollary of these considerations is that consumers may respond asymmetrically depending upon whether Sunday sales hours rise or fall. In a state where a Sunday off-premises sales ban has been in place for a long time, consumers may have tailored their self-control strategies to exploit it, for example by making sure not to stock up on liquor before a weekend. In contrast, in a state where Sunday off-premises sales have always been permitted, consumers may have developed other self-control techniques. Significantly, the aggregate efficacy effect will be higher in the first instance, where usage of the availability strategy is initially more widespread, than in the second. This is fortunate from our perspective because, in general, states progressively liberalized their Sunday sales restrictions during the period we study.

\section{Data}

Characterizing the evolution of each state's alcohol sales policies from 1970 through 2007 involved laborious archival research. We began by identifying the most recent statutes for each state. Using the amendment dates listed in the notes of the current statutes, we then searched for the pre-amended statutes, from which we determined the nature of the changes to the alcohol control laws. We collected information on the number of allowable hours for both on- and off-premises sales as well as the legal drinking age, in all cases noting whether localities were given discretion to set either more or less restrictive rules. We supplemented this information with data compiled by the Distilled Spirits Council of the United States and published in its annual handbooks, which were available for a portion of the pertinent time period.

Stehr (2007) describes the patchwork of state alcohol regulations as Byzantine, but even that term understates their variety and complexity. For instance, some states prohibit the sale of alcohol unless food is also served; others have complicated rules that depend on a county's population. In many instances we found it challenging to characterize these laws along simple measurable dimensions. As a general rule, we measured allowable hours based on the least stringent statewide default rule, even if local jurisdictions were granted and frequently exercised discretion to deviate from the default. In cases where laws provide for contiguous hours of operation after 
midnight, we associated those hours with the previous day; for example, if a state allows sales from 10am on Saturday to 2am on Sunday but not otherwise on Sunday, we recorded 16 hours for Saturday and zero hours for Sunday. Several states provide no default and leave the regulation of hours (either on-premises, off-premises, or both) entirely up to local governments; three states did so for part of the period we study. We dropped the associated observations from the sample. Ultimately, we arrived at restrictions on liquor sales applicable to each state in each year, thereby matching the unit of observation for our dependent variable, the volume of liquor sales (see below). This necessitated the adoption of a coding convention for policies that were changed partway through a year. Our convention was to treat a new law as in effect throughout the calendar year in which it was implemented. In Section 5.2, we show that this convention is not responsible for our findings.

Between 1970 and 2007, fifteen states repealed blue laws banning off-premises liquor sales on Sunday and fourteen states did so for on-premises sales. Including these repeals, twentyone states modified allowable off-premise Sunday sales hours a total of thirty-four times, while thirty states modified allowable on-premise Sunday sales hours a total of forty-six times. In almost every instance, restrictions on Sunday liquor sales were relaxed. All such changes are listed in Table 1.

Annual state-level data on liquor sales in gallons of pure ethanol equivalent come from the National Institute on Alcohol Abuse and Alcoholism (NIAAA). Using Census Bureau population data, we convert these figures into gallons of pure ethanol per person over the age of 18. An obvious limitation of these data is that they are highly aggregated, not only across individuals, but also across off-premises and on-premises sales. While aggregate data suffice for the purpose of testing the hypotheses outlined in Section 3, they do not permit us to explore population heterogeneity with respect to the demand for and use of commitment devices.

Since the NIAAA data describe in-state sales rather than in-state consumption, our results necessarily encompass effects on cross-border traffic (see, for example, Lovenheim and Slemrod, 2010, on evasion of the legal drinking age). To separate cross-border effects from the impact on consumption among a state's residents, we control for differences between the regulations of neighboring states using two sets of variables, which we describe below. For numerical illustrations and further discussion of these variables, see the appendix. 
The first set of variables is designed to control for the possibility that residents of the border counties of neighboring states travel into a state that has laxer laws than their own. For each state, we compute the number of allowable Sunday sales hours in excess of each of its neighbors (zero if it has shorter hours). We then multiply these excess hours by the number of people living in the border counties of the neighboring state, and sum over all neighbors to obtain the total number of potential person-hours driving inflows of customers (outflows of liquor). Finally, we divide by the original state's population to scale the variable in the same way as our dependent variable. We call the resulting variables OnInflows and OffInflows for on-premises and off-premises hours, respectively.

The second set of variables is designed to control for the possibility that the state's residents cross borders to purchase alcohol in other states. For each state, we compute excess Sunday sales hours for each of its neighbors (i.e., the difference between the neighbor's hours and the state's hours, truncated below at zero). We then multiply these excess hours by the number of people living in the border counties of the subject state, and sum over all neighboring states to obtain the total number of potential person-hours driving outflows of customers (inflows of liquor). Again we divide by the subject state's population so that the variables reflect comparable scaling. We call these variables OnOutflows and OffOutflows for on-premise and off-premise hours, respectively. These measures are similar to variables used by Stehr (2007), who employs an indicator for a Sunday sales ban instead of the difference in hours of sale.

Table 2 shows summary statistics. The mean consumption in our sample is nearly one gallon of ethanol equivalent per adult per year, though there is substantial heterogeneity both within and across states. The unconditional means for on- and off-premises Sunday sales hours are 10.0 and 4.9, respectively; conditional on positive hours, the means are 15.8 hours and 14.0 hours. Per-capita consumption is 5.5 percent higher for observations pertaining to states and years for which Sunday on-premise sales were allowed, compared with those for which such sales were not allowed, and 16 percent higher for observations pertaining to states and years for which Sunday off-premise sales were allowed, compared with those for which such sales were not allowed. However, these simple comparisons do not account for unobserved cross-state variation in attitudes toward alcohol that likely affect both Sunday sales restrictions and consumption; nor do they account for other alcohol regulations or broader trends. 


\section{Results}

\subsection{Specification}

The unit of observation in our analysis is a state-year. For all the specifications reported here, we regress the log of annual per capita ethanol-equivalent liquor sales on variables capturing Sunday on-premises and off-premises sales restrictions, state fixed effects (to capture differences in attitudes toward alcohol across states), year fixed effects (to capture general trends in alcohol consumption, macroeconomic activity, and other time-varying factors), and other controls. Thus, our central identifying assumption is that there are no systematic differences in unobserved factors affecting trends in alcohol consumption between states that do and do not change their policies regarding Sunday liquor sales. We employ standard diagnostics to evaluate the validity of that identifying assumption below. In all cases, the additional controls include variables capturing liquor and cigarette taxes, ${ }^{7}$ the legal drinking age, provisions allowing local governments to expand or restrict Sunday sales hours relative to the statewide default, ${ }^{8}$ the state's unemployment rate, and the state's total population. In light of the fact that the specifications include state and year fixed effects, the last two variables capture economic and social conditions that are distinctive for the state and year in question -- for example, they allow for the possibility that alcohol consumption rises when economic conditions are poor, or follows a different trend in states experiencing rapid population growth.

Our specifications relate liquor consumption to the number of Sunday hours during which sales are allowed. As an alternative, one could examine the relationship between consumption and a binary variable indicating whether sales are permitted at any point during the day, as in Stehr (2007) for example. In light of our study's objectives, the "hours" specification is preferable under the view, expressed in Section 3.3, that a lapse of self-control could potentially occur at any point during the day. In contrast, the binary specification is more appropriate if these potential lapses are concentrated at times of day that always fall within allowable sales hours when Sunday sales are permitted. In choosing between the "hours" and binary specifications, it is therefore important to ask whether, apart from outright bans, the variation in Sunday hours occurs at times when people may be tempted to purchase liquor. The following three considerations imply that it does.

\footnotetext{
${ }^{7}$ The data on taxes were compiled and generously provided by Mark Stehr (see Stehr, 2007).

${ }^{8}$ Of the fifty-six legislative events that relaxed restrictions on Sunday sales hours (either on- or off-premises), thirteen were accompanied by changes in local governments' discretion to set either more or less restrictive rules.
} 
First, people drink alcohol throughout the day on Sundays. We can infer this, for example, from data on self-administered smartphone breathalyzer tests. Of the tests administered during a 24 hour period starting at 6am on the typical Sunday, roughly 12\% occur between Sunday 6am and noon, and more than 20\% occur between Sunday noon and 6pm (BACTrac Breahtalyzers, Inc., 2014). While the frequency of tests increases over the course of the day, it is important to bear in mind that the timing of a BAC test more reliably indicates when a drinking session ends than when it begins; accordingly, these data capture alcohol consumption with a significant lag. The prevalence of drinking throughout the day on Sundays should come as no surprise. Bloody Marys, mimosas, and the like are popular fare at Sunday brunches (see, for example, Joseph, 2012). Drinking is also notoriously linked to sporting events such as Sunday professional football games, and often starts before the events begin (see, for example, the analysis of "tailgating" in Merlo et al., 2011).

Second, regardless of when consumption occurs, events that trigger purchases can happen throughout the day. A consumer's ability to resist the urge to make a "liquor run" likely varies over the course of a day with their activities and experiences (as discussed in Bernheim and Rangel, 2004). For example, their willpower may falter when they anticipate watching a sporting event or getting together with friends who drink. Advertisements for alcohol, which are particularly common during televised sporting events at all hours of the day, can serve as particularly potent cues (Meier, 2011). Thus, every hour of allowable liquor sales presents new opportunities for consumers to succumb. Significantly, even if people drink more at 6pm than at 11am, a triggering event that occurs at 11am can have a larger effect on total consumption over the course of the day by inducing the consumer to stock up sooner.

Third, the observed changes in sales hours do not follow a fixed pattern. In many cases states allowed sales earlier in the day, but in some instances they also permitted later sales. For example, Pennsylvania extended on-premises hours first in one direction and then in the other (1pm to 10pm prior to 1975, 1pm to 2am Monday between 1975 and 1984, and 11am to 2am Monday after 1984), while Iowa extended on-premises and off-premises hours in both directions at the same points in time (12pm to 10pm prior to 1984, 10am to midnight from 1984 to 1991, and 8am to 2am Monday after 1991).

Based on these three considerations, we conclude that the variation in Sunday sales hours occurs at times of day when people are likely tempted to purchase liquor, and consequently that 
the hours specification is preferable for our purposes. The binary specification disregards relevant variation in liquor sales restrictions and inappropriately treats diverse policies as homogenous.

To interpret the magnitudes of the estimated effects, it is useful to know the fractions of total liquor consumption attributable to on-premises and off-premises Sunday drinking. To our knowledge, direct estimates of those fractions are not available. On the basis of indirect evidence, it appears that on-premises Sunday drinking accounts for between 6 and 10 percent of total liquor consumption, while off-premises Sunday drinking accounts for between 10 and 14 percent. $^{9}$ Therefore, if an on-premise ban suppressed all on-premise Sunday drinking without causing substitution to other days, we would expect total alcohol sales to fall by 6 to 10 percent; similarly, if an off-premise ban suppressed all off-premise Sunday drinking, we would expect total alcohol sales to fall by 10 to 14 percent.

For all specifications reported below, we cluster standard errors at the state level. In the interests of brevity, we report coefficients only for key variables that capture aspects of policies targeting alcohol consumption. See the Appendix for complete regression results, as well as for estimates of other specifications referenced in the text.

\subsection{Main Results}

Column (1) of Table 3 reports estimates for our main specification. Widening the allowable on-premise Sunday sales window by one hour is associated with a statistically significant 0.94 percent (s.e. $=0.29$ percent) increase in sales. Taking the linear specification literally, the point estimate implies that allowing twelve hours of Sunday on-premises sales increases total liquor consumption by roughly 11 percent. That estimate is somewhat larger than expected in light of the fact that, when allowed, Sunday on-premises sales likely account for less than 10 percent of liquor consumption, but a standard confidence interval contains reasonable magni-

\footnotetext{
${ }^{9}$ As a crude estimate of the fraction of liquor consumed on Sundays, one-seventh (14\%) is conservative because people tend to drink more alcohol on weekends than on weekdays (Zegler, 2013). Other evidence suggests that the actual figure is in the neighborhood of $20 \%$. For example, roughly $18.3 \%$ of self-administered smartphone breathalyzer tests are performed between 6am Sunday morning and 6am Monday morning (BACtrack Breathalyzers, Inc., 2014). In 2000, on-premises purchases accounted for $53 \%$ of household spending on liquor (Paulin, 2003; see also Bloom, 2012, and Zegler, 2012). Thus, if the price of liquor were the same on premises and off premises, onpremises Sunday purchases would account for about $10.6 \%$ of total liquor consumption. In fact, liquor is more expensive on premises than off premises. If we assume (consistent with some anecdotal evidence and "soft" numbers taken from the popular press) that restaurants and bars purchase liquor in bulk at a wholesale discount of $33 \%$ and sell it with a 300\% markup over cost, then equal spending implies that on-premises liquor sales account for about $30 \%$ of Sunday consumption, or $6 \%$ of total consumption, while off-premises liquor sales account for about $70 \%$ of Sunday consumption, or $14 \%$ of total consumption.
} 
tudes. It is also possible that the effect is not perfectly linear, and that much of the observed variation in sales hours happens to occur at high-impact times of day.

In contrast, expanding the allowable off-premise Sunday sales window by one hour is associated with a small and statistically insignificant 0.08 percent (s.e. $=0.24$ percent) increase in sales. Formally, we cannot reject the hypothesis that the effect of off-premises sales hours is zero. The absence of a relationship between liquor consumption and allowable off-premises sales hours is inconsistent with the notion that significant numbers of consumers use the availability strategy, especially because other considerations such as forgetfulness and inventory-carrying costs would, if anything, tend to augment the estimated effect (as explained in Section 3).

An inherent limitation of our approach is that a confidence interval centered at zero will always include positive numbers, and hence one cannot hope to reject a positive effect in favor of zero. Moreover, given the size of the actual confidence interval, we cannot formally reject the hypothesis that a meaningful fraction of consumers employ the availability strategy. That said, our failure to reject the absence of an off-premises effect is not a matter of imprecision. Rather, it reflects the small magnitude of the point estimate. Indeed, as we will see, the point estimates for alternative specifications cluster around zero, with some slightly positive and some slightly negative. The slightly positive coefficient for this particular specification implies that allowing twelve hours of Sunday off-premises sales increases total liquor consumption by roughly one percent. To put this figure in perspective, recall that if an off-premises ban suppressed all offpremises Sunday drinking, we would expect total alcohol sales to fall by 10 to 15 percent. The contrast between the estimated on-premises and off-premises effects is also striking in this regard. We have no difficulty rejecting the hypothesis that the effect of on-premises sales hours is zero, even though the on-premises coefficient is estimated less precisely. Moreover, even though the volume of off-premises liquor sales is considerably greater than that of on-premises sales, the difference between the estimated off-premises effect and the much larger on-premises effect is statistically significant at $\mathrm{p}=0.07$.

Other effects in column (1) are also of interest. ${ }^{10}$ As expected (and consistent with the findings in Stehr, 2007), higher taxes on both liquor and cigarettes (which are complementary to liquor) reduce liquor consumption, and the effects are statistically significant. We are unable to

\footnotetext{
${ }^{10}$ In addition to the effects discussed in this paragraph, the neighboring state controls are jointly significant $(\mathrm{p}=$ 0.006), with OffInflows and OnOutflows individually statistically significant, but some of the signs are counterintuitive.
} 
detect a systematic relationship between liquor consumption and the legal drinking age despite significant variation in this variable prior to the mid-1980s, ${ }^{11}$ but the estimated effects are imprecise. A local option to expand allowable hours relative to the state default increases sales by 1.2 percent (s.e. = 2.3 percent), and a local option to restrict hours reduces sales by 4.6 percent (s.e. $=2.3$ percent); only the latter effect is statistically significant.

The size of our data sample is somewhat constrained by the inclusion of controls for liquor and cigarette taxes, which we do not have for years before 1981. We use these controls to address a potential confound: if legislatures relax Sunday sales restrictions with the aim of increasing tax revenues, they may well raise tax rates simultaneously. Such occurrences would tend to offset any increase in alcohol sales resulting from longer sales hours. That said, dropping these variables allows us to add eleven years of data, which offers other potential advantages. Results appear in column (2) of Table 3. Our findings do not change appreciably, except that the estimated effect of a local option to expand allowable Sunday sales hours is now statistically significant.

In Section 3, we observed that the effects of a change in off-premise sales hours on the efficacy of the availability strategy, and hence on alcohol purchases, may differ according to the length of on-premise sales hours. In particular, the implication that those using the availability strategy should increase off-premise purchases in response to longer off-premise sales hours follows most cleanly when on-premise hours do not exceed off-premise hours. Thus, at least as a matter of principle, our failure to detect a significant effect of off-premise hours could be attributable to the fact that on-premise hours tend to be longer than off-premise hours. ${ }^{12}$ To test this possibility, we added an interaction term between on-premise and off-premise hours to the specification. If lengthening on-premises sales hours weakens the effect of limiting off-premise hours, then the coefficient of the interaction term should be negative. In fact, as shown in Column (3) of Table 3, that coefficient is small, positive, and statistically insignificant; moreover, the coefficient of off-premise hours becomes slightly negative. Consequently, we can rule out the possibility that the effect of off-premises hours has been muted by substitution to on-premises consumption.

\footnotetext{
${ }^{11}$ There were 74 changes in the legal drinking age in our sample, all of which were confined to 24 of the 47 states., with 21 occurring in 1985 and 1986 in response to federal pressure.

${ }^{12}$ Off-premise hours exceeded on-premise hours only in South Dakota.
} 
In addition to regulating Sunday sales hours, some states also limit liquor sales on Saturdays and weekdays. Yet our basic specification does not include controls for non-Sunday restrictions. We formulated the specification this way for three reasons.

First, changes in non-Sunday restrictions were relatively rare, and generally much smaller than changes in Sunday restrictions. As a result, we doubted that we would be able to measure their effects with useful precision. For example, there were only 15 changes in maximum onpremises weekday sales hours in our sample, and those were confined to 10 states. The change exceeded one hour only seven times, and exceeded three hours only three times (those changes being 4, 9, and 11.5 hours). In contrast, there were 46 changes in maximum on-premises Sunday sales hours in our sample, and those were distributed over 30 states. The change was at least 10 hours thirteen times, and at least 4 hours twenty times.

Second, non-Sunday sales restrictions were only modestly correlated with Sunday restrictions. Altogether, only 21 percent of changes in Sunday off-premises restrictions and 26 percent of changes in Sunday on-premises restrictions also affected other days. Allowable hours on weekdays, Fridays, and Saturdays were all highly correlated with each other, but they were much less correlated with allowable Sunday hours. For example, for allowable on-premises sales hours, weekday and Friday restrictions were highly correlated $(\rho=0.998)$, as were weekday and Saturday restrictions $(\rho=0.993)$, but the correlation between weekday and Sunday restrictions was comparatively modest $(\rho=0.271)$.

In light of the fact that changes in non-Sunday restrictions were relatively rare, small, and only modestly correlated with changes in Sunday restrictions, we inferred that the omission of associated controls would likely have a small impact on the coefficients of interest. But even if the impact were substantial, we would be untroubled, due to our third point: the hypotheses of interest pertain to the effects of sales restrictions in general, rather than Sunday restrictions in particular. At worst, leaving out controls for non-Sunday restrictions would necessitate a reinterpretation of magnitudes. Moreover, given that Sunday and non-Sunday changes coincide with similar frequencies for on-premises and off-premises restrictions, there is no reason to think that this consideration meaningfully impacts comparisons between estimates of their effects.

In any case, it is certainly possible to estimate specifications that include measures of allowable non-Sunday hours; see column (4) of Table 3. Our expectations are confirmed: the coefficients of these variables are imprecisely estimated, of the wrong sign, and not statistically sig- 
nificant. Notably, the coefficient of allowable on-premises Sunday hours is virtually unaffected, while that of allowable off-premises hours remains insignificant and becomes slightly negative.

\subsection{Tests of the Identifying Assumptions}

As mentioned above, our central identifying assumption is that there are no systematic differences in unobserved factors affecting trends in alcohol consumption between states that do and do not change their policies regarding Sunday liquor sales. Thus, a threat to identification arises from the possibility that changes in Sunday sales restrictions were correlated with other state-specific developments that also influenced alcohol consumption.

One concern is that causality may flow in the opposite direction: legislators may have responded to increasing consumer demand for liquor by relaxing restrictions. Notice, however, that this consideration would tend to bias the coefficients of interest upward. Consequently, it cannot account for the absence of a significant relationship between liquor consumption and offpremises sales hours, which is our central finding. Moreover, based on our reading of the historical record, it appears more likely that liberalizations of sales hours have been driven primarily by orthogonal concerns about tax revenues. Still, the issue merits further investigation.

A second concern is that relaxations of Sunday sales restrictions may have caused public and private organizations to intensify interventions aimed at limiting alcohol abuse. Notice that this consideration, unlike the last one, would tend to bias the coefficients of interest downward. Thus, it raises the possibility that we might find no significant relationship between liquor consumption and Sunday sales hours even when one exists. Of course, were this an important confound, we would expect it to have similar effects on the estimated coefficients of allowable onpremises and off-premises sales hours. In fact, there is no indication that the on-premises coefficient is meaningfully attenuated. Still, this concern also merits further investigation.

We address these issues by exploring more carefully the timing of the relationships between expanded sales hours and increased alcohol sales. This is an effective strategy provided the potentially confounding state-specific changes were not precisely synchronized with the policy changes of interest. It is certainly reasonable to assume that, if legislative action resulted from trending liquor demand, the trend must have started prior to the legislation, and it likely resulted in smooth growth over a period of years rather than a sudden surge in purchases. Similarly, if the relaxation of Sunday sales restrictions led to the intensification of interventions designed to 
limit alcohol abuse, those efforts may well have started prior to (and in anticipation of) the change, and/or they may have evolved and gradually intensified afterwards.

We began our investigation by adding the one-year leads of allowable on-premise and off-premise Sunday sales hours to specification (1) from Table 3; see Column (1) of Table 4. If some of the concerns described above are indeed serious, the coefficients of the leads should be relatively large, indicating elevated consumption prior to the change in the law. Yet those coefficients are quite small and statistically insignificant. Notably, the addition of the leads reduces the coefficient for allowable on-premises sales hours to a more plausible magnitude. The coefficient for allowable off-premise sales hours also falls slightly to 0.0002 percent (s.e. $=0.26$ percent). Including two leads does not change these results appreciably, as seen in Column (2) of Table 4.

Next, we estimated specifications including lags of the key policy variables, which could enter with significant coefficients for a variety of reasons: there may have been confounding trends in demand, liquor sales may have responded gradually to changes in sales hours, liberalization of Sunday sales restrictions may have led to progressive intensification of offsetting interventions, the typical law may have been implemented partway through the pertinent calendar year (as noted in Section 4), or consumers may have initially provided for higher liquor consumption after the policy change at least in part by drawing down their inventories. As shown in Column (3) of Table 4, the coefficients of the lags are small and statistically insignificant, and our estimates of the effects of interest are largely unchanged. While the measurement of lagged effects does not permit us to distinguish between the various possibilities mentioned at the start of this paragraph, there is no indication that any of these considerations are important confounds.

Finally, we estimated specifications that included interactions between a linear time trend and two dummy variables, one indicating whether a state ever changed off-premise sales restrictions during the sample period, and the other indicating whether it ever changed on-premise restrictions. Results appear in Column (4) of Table 4. The coefficients of the trend variables are small and statistically insignificant, and the main effects of interest remain largely unchanged. ${ }^{13}$

\footnotetext{
${ }^{13}$ An even more flexible specification would include state-specific linear trends, but this demands a great deal from the data and leaves too little variation for identifying the effects of interest. The off-premises coefficients are largely unaffected, but (predictably) the on-premises effects become statistically insignificant.
} 
Based on these tests, we find strong support for the central identifying assumption underlying our analysis. ${ }^{14}$ We acknowledge that this investigation does not allow us to rule out the possibility that changes in Sunday off-premise sales hours led to perfectly synchronized and perfectly offsetting adjustments in anti-alcohol interventions, but our failure to find clear indications of an attenuated coefficient for on-premises sales restrictions (to which the same confound ought to apply) casts doubt on this alternative interpretation. In addition, we report below estimates of a specification that includes control variables measuring wine and beer consumption, which arguably proxy for a wide range of unmeasured factors that may influence the general demand for alcohol. While the coefficients of these variables are indeed highly significant, their inclusion does not alter the effects of interest.

\subsection{Additional Robustness Checks}

In light of the fact that we find a sizable effect of cigarette taxation on liquor consumption, one possible concern is that we may have controlled inadequately for the full range of policies that affect smoking. The most directly pertinent policies are those pertaining to smoking in places where people tend to consume alcohol. Accordingly, we added a dichotomous variable indicating whether state law prohibits smoking in bars. Results appear in column (1) of Table 5. The effects of bans are statistically insignificant $(-0.004$, s.e. $=0.026)$, and the inclusion of this variable does not affect our main results.

Another possible concern is that changes in regulations affecting the sale of liquor may have coincided with similar changes affecting wine and beer. ${ }^{15}$ To the extent liquor, wine, and beer are substitutes, such occurrences could potentially confound our results. We examine this possibility in two ways. First, we investigate whether the inclusion of tax rates for wine and beer affect our conclusions; they do not. As seen in Column (2) of Table 5, neither of those tax rates has a statistically significant effect on the consumption of liquor, and the coefficients for allowable hours of liquor sales are largely unchanged. Second, to control broadly for policies affecting

\footnotetext{
${ }^{14}$ We also estimated versions of specifications (1) through (3) in Table 4, using dichotomous variables (indicating whether or not Sunday sales are allowed at all) rather than measures of allowable hours for the lags and leads. The results are extremely similar to those reported in the table. In all cases, the coefficients of allowable off-premises hours are slightly negative and statistically insignificant, while those of allowable on-premises hours are large and statistically significant. The leads and lags themselves are statistically insignificant.

${ }^{15}$ Separately, we also examined whether Sunday sales hours for wine and beer affected wine and beer consumption, but the results were inconclusive. As we noted in the introduction, the results for liquor speak most directly and reliably to the hypotheses of interest because self-control problems are more prevalent for liquor (Kerr et al., 2002, and Roizen et al. 1999), and because our measures of sales restrictions are "noisier" for wine and beer (given that the restrictions themselves are more complicated).
} 
wine and beer, we add variables measuring the total consumption of both. As mentioned above, those variables also arguably proxy for a wide range of unobserved factors generally influencing alcohol consumption. Note that they enter with large, statistically significant coefficients. This result is not surprising given that unobserved preferences for different types of alcohol are likely positively correlated, and that environments favoring the consumption of one type of alcohol will also likely favor the consumption of others. Still, the addition of these variables has virtually no effect on the coefficients of interest.

In Section 5.1, we explained our reasons for adopting specifications that relate liquor consumption to the number of allowable sales hours rather than to binary variables indicating whether liquor sales are permitted at some point during the day. Recall in particular that binary specifications disregard variation in sales restrictions that shed useful light on the hypotheses of interest. At best, they allow us to measure the effect of eliminating a Sunday ban, averaged across a relatively small number of events wherein bans give way to a heterogeneous assortment of restrictions. Significantly, only 21 of the 60 events listed in Table 1 involved the elimination of a ban on Sunday sales. Accordingly, binary specifications attempt to identify the two effects of interest based on barely more than one-third of the events that provide identification in the "hours" specifications -- that is, from roughly 10 events per effect.

Because binary specifications are both conceptually flawed for our purposes and severely underpowered, we place little stock in them. However, to facilitate comparisons with some related studies, we nevertheless report one in column (4) of Table 5. Notably, the estimated coefficients for on-premises and off-premises restrictions imply a combined effect comparable to that reported in Stehr (2007). However, compared with our other estimates, there is a striking (and anticipated) loss of precision. From one perspective, the results are qualitatively similar: the effect of an on-premises ban is large and statistically significant, while that of an off-premises ban is smaller and statistically insignificant. However, from another perspective, the cost of discarding two-thirds of the relevant variation in sales restrictions is readily evident. In this instance, our failure to reject the absence of an off-premises effect results from the large standard error rather than the magnitude of the pertinent coefficient, which, though still noticeably smaller than its on-premises counterpart, is consistent with a reasonably large impact on alcohol sales. In addition, we can no longer reject equality of the on-premises and off-premises effects. 
It is important to emphasize that the inconclusiveness of results based on binary specifications does not undermine our main findings. It simply demonstrates that one cannot usefully address the hypotheses of interest by confining attention to absolute bans on Sunday liquor sales. Once one also exploits highly relevant variation in allowable sales hours, the data speak to those hypotheses with reasonable clarity.

\section{Conclusions}

Taken as a whole, our results indicate that consumers increase their liquor consumption in response to extended Sunday on-premise sales hours, but not in response to extended offpremise sales hours. While our analysis uncovers no indication that off-premise sales hours affect alcohol purchases, it does not prove that such an effect is absent. As always, it is impossible to reject the hypothesis that an effect is non-zero. Still, in all specifications the pertinent coefficients cluster near zero, and consequently we fail to reject the hypothesis that the demand for commitment via the availability strategy is absent. Most strikingly, we fail to detect an effect of off-premise sales hours even though we easily detect a strong effect for on-premise sales hours. That disparity is at odds with the hypothesis that the demand for commitment via the availability strategy is prevalent.

Thus, to our considerable surprise, we find no indication that commitment strategies affecting availability play meaningful roles in aggregate liquor consumption. Instead, the observed pattern coincides with predictions for time-consistent or naively time-inconsistent consumers who have reasonably good memories and low costs of carrying inventories. Though the aggregated nature of the available data on liquor consumption precludes us from exploring population heterogeneity with respect to the demand for and use of commitment devices, we can nevertheless infer that use of the availability strategy is likely not widespread. Our findings also have important implications concerning tax policy and public health. Measures that relax restrictions pertaining to on-premise liquor sales are likely to increase state tax revenue, but may also entail greater alcohol-related social costs. However, measures that relax restrictions pertaining to offpremise liquor sales are unlikely to have either effect. 


\section{References}

Amador, Manuel, Iván Werning, and George-Marios Angeletos (2006). "Commitment vs. Flexibility.” Econometrica 74(2): 365-396.

Anton, R. F.(2001). "Pharmacological approaches to the management of alcoholism." Journal of Clinical Psychiatry, Vol. 62(supp 20):11-17.

Ariely, Dan and Klaus Wertenbroch. (2002). "Procrastination, Deadlines, and Performance: SelfControl by Pre-Commitment."Psychological Science 13(3): 219-224.

Ashraf, Nava, Dean Karlan and Wesley Yin. (2006). "Tying Odysseus to the Mast:Evidence from a Commitment Savings Product in the Philippines.” Quarterly Journal of Economics 121(2): 635-672.

Becker, Gary and Kevin Murphy. (1988). “A Theory of Rational Addiction.” Journal of Political Economy, Vol. 96, No. 4, pp. 675-700.

BACTrac Breathalyzers, Inc., "BACtrack ${ }^{\circledR}$ Consumption Report.” http://www.bactrack.com/pages/bactrack-consumption-report-winter-2014. February 2014, accessed 10/9/15.

Banerjee, Abhijit, and Sendhil Mullainathan (2010). "The Shape of Temptation: Implications for the Economic Lives of the Poor.” Mimeo, MIT.

Bernheim, B. Douglas, Andrey Fradkin, and Igor Popov. (2015). "The Welfare Economics of Default Options in 401(k) Plans.” The American Economic Review, Vol. 105, No. 9, forthcoming.

Bernheim, B. Douglas and Antonio Rangel. (2004). "Addiction and Cue-Triggered Decision Processes.” The American Economic Review, Vol. 94, No. 5, pp. 1558-1590

Bernheim, B. Douglas, Debraj Ray, and Sevin Yeltekin. (2015). "Poverty and Self-Control.” Econometrica. Forthcoming.

Beshears, J., J. Choi, C. Harris, D. Laibson, B. Madrian, J. Sakong, "Self Control and Commitment: Can Decreasing the Liquidity of a Savings Account Increase Deposits?" NBER WP 21474, August 2015.

Bryan, Gharad, Dean Karlan and Scott Nelson. (2010). “Commitment Devices.”Annual Review of Economics. Vol. 2: 671-698.

Carpenter, Christopher and Daniel Eisenberg. (2009). "The Effects of Sunday Sales Restrictions on Overall and Day-Specific Alcohol Consumption: Evidence from Canada.” Journal of Studies on Alcohol and Drugs. Vol. 70, No. 1, pp 126-133. 
Bloom, Beth. White Spirits and RTDs - US - November 2012. Mintel Group Ltd.

Choi, Laibson, Madrian. (2011). "100-dollar Bills on the Sidewalk: Violations of no-arbitrage in 401(k) Accounts.” Review of Economics and Statistics. Forthcoming.

Collins, R. Lorraine (1993), “Drinking Restraint and Risk for Alcohol Abuse,” Experimental and Clinical Psychopharmacology 1(1-4), 44-54.

DellaVigna, Stefano, and Ulrike Malmendier. (2004). "Contract Design and Self-Control: Theory and Evidence,” Quarterly Journal of Economics, Vol. 119, No. 2, pp. 353-402.

DellaVigna, Stefano. (2009). "Psychology and Economics: Evidence from the field.” Journal of Economic Literature 47(2): 315-372.

Distilled Spirits Council of the United States. Summary of State Laws and Regulations Relating to Distilled Spirits. Washington, D.C. Various years.

Diamond, Peter, and Botond Koszegi (2003). "Quasi-Hyperbolic Discounting and Retirement.” Journal of Public Economics 87(9-10): 1839-1872.

Dupas, P., and J. Robinson, "Why don't the poor save more? Evidence from health savings experiments," American Economic Review 103(4), 2013, 1138-71.

Fang, Hanming, and Daniel Silverman (2009). "Time-Inconsistency and Welfare Program Participation: Evidence from the NLSY.” International Economic Review, 50(4): 1043-1077.

Gine, Xavier, Dean Karlan, and Jonathan Zinman. (2010). "Put Your Money Where Your Butt Is: A Commitment Contract for Smoking Cessation.” American Economic Journal: Applied Economics 2(4): 213-25.

Gruber, Jonathan and Botond Koszegi. (2001). "Is Addiction "Rational”? Theory and Evidence.” The Quarterly Journal of Economics 116(4): 1261-1303.

Gul, Faruk and Wolfgang Pesendorfer. (2001). "Temptation and Self-Control.” Econometrica, Vol. 69, No. 6, pp. 1403-1435.

Halpern, Scott D., Benjamin French, Dylan S. Small, Kathryn Saulsgiver, Michael O. Harhay, Janet Audrain-McGovern, George Loewenstein, Troyen A. Brennan, David A. Asch, and Kevin G. Volpp, "Randomized Trial of Four Financial-Incentive Programs for Smoking Cessation," New England Journal of Medicine 372, 2015, 2108-2117.

Harding, Matthew, Ephraim Leibtag, and Michael Lovenheim. (2012). “The Heterogeneous Geographic and Socioeconomic Incidence of Cigarette Taxes: Evidence from Neilsen Homescan Data.” American Economic Journal: Economic Policy, 4(4): 169-198. 
Heaton, Paul. (2012). "Sunday Liquor Laws and Crime.” Journal of Public Economics. Vol. 96, No. 1-2, pp. 42-52.

Hinnosaar, Marit. (2012). “Time Inconsistency and Alcohol Preferences.” Working Paper.

Houser, Daniel, Daniel Schunk, Joachim Winter, and Erte Xiao. (2010). "Temptation and Commitment in the Laboratory,” Institute for Empirical Research in Economics, University of Zurich, Working Paper No. 488.

Hughes, J. C., and C. C. H. Cook. (1997). "The efficacy of disulfiram: a review of outcome studies.” Addiction, Vol. 92, pp. 381-395.

Joseph, Peter. Boozy Brunch: The Quintessential Guide to Daytime Drinking. Taylor Trade Publishing, 2012.

Kerr, William, Kay Middleton Fillmore, and Paul Marvy. "Beverage-specific alcohol consumption and cirrhosis mortality in a group of English-speaking beer-drinking countries." Addiction, 95(3): 339-346.

Kaur, S., M. Kremer, and S. Mullainathan, "Self-Control at Work," Journal of Political Economy, 2015, forthcoming.

Krusell, Per, Burhanettin Kuruscu andAnthony Smith (2000). "Tax Policy With QuasiGeometric Discounting.” International Economic Journal 14(3): 1-40.

Laibson, David (1997). “Golden Eggs and Hyperbolic Discounting.” Quarterly Journal of Economics, 112(2): 443-78.

Laibson, David (1998). "Life-Cycle Consumption and Hyperbolic Discount Functions.” European Economic Review 42: 861-871.

Laibson, David, Andrea Repetto, and Jeremy Tobacman (1998). "Self-Control and Saving for Retirement.” Brookings Papers on Economic Activity, 1: 91-172.

Ligon, Janand Bruce Thyer. (1993). "The Effects of a Sunday Liquor Sales Ban on DUI Arrests.” Journal of Alcohol and Drug Education, 38: 33-40.

Lovenheim, Michael, and Joel Slemrod. (2010). "The fatal toll of driving to drink: The effect of minimum legal drinking age evasion on traffic fatalities.” Journal of Health Economics, 29(1): 62-77.

Lovenheim, Michael and Daniel Steefel. (2011). "Do Blue Laws Save Lives? The Effect of Sunday Alcohol Sales Bans on Fatal Vehicle Accidents.” Journal of Policy Analysis and Management. Vol. 30, No. 4, pp. 798-820. 
McMillan, Garnett P. and Lapham, Sandra. (2006). “Legalized Sunday Packaged Alcohol Sales and Alcohol-Related Traffic Crashes and Crash Fatalities in New Mexico.” American Journal of Public Health, 96(11): 1944-1948.

Meier, P.S., “Alcohol Marketing Research: The Need for a New Agenda,” Addition 106(3), 2011, 466-471.

Merlo, Lisa J., Brian K. Ahmedani, David A. Barondess, Kipling M. Bohnert, and Mark S. Gold, "Alcohol Consumption Associated with Collegiate American Football Pre-Game Festivities," Drug and Alcohol Dependence 116(1-3), 2011, 242-245.

National Highway Traffic Safety Administration (NHTSA), National Center for Statistics and Analysis (2003). 2002 Annual Assessment of Motor Vehicle Crashes Based on the Fatality Analysis Reporting System, the National Accident Sampling System and the General Estimates System. Washington, DC: U.S. Department of Transportation.

National Institute on Alcohol Abuse and Alcoholism, "Tips to Try," Rethinking Drinking: Alcohol \& Your Health, http://rethinkingdrinking.niaaa.nih.gov/Strategies/TipsToTry.asp, accessed January 9, 2012.

O’Donoghue, Ted and Matthew Rabin. (1999). “Doing It Now or Later.” The American Economic Review, Vol. 89, No. 1, pp. 103-124.

O’Donoghue, Ted and Matthew Rabin. (2001). “Choice and Procrastination.” Quarterly Journal of Economics, Vol. 116, No. 1, pp. 121-160.

Olsson, O. and P.O.H. Wikstrom. (1982) "Effects of the experimental Saturday closing of liquor retail stores in Sweden.” Contemporary Drug Problems, 11:325-353.

Ornstein, Stanley I. and Hanssens, Dominique M. (1985). "Alcohol Control Laws and the Consumption of Distilled Spirits and Beer.” The Journal of Consumer Research, 12(2): 200-213.

Paulin, Geoffrey (2003), “Consumer Expenditures for Alcohol in 2000,” Consumer Expenditure Survey Anthology, 39-59.

Rand, Michael R., William J. Sabol, Michael Sinclair, and Howard Snyder (2010), “Alcohol and Crime: Data from 2002 to 2008,” mimeo, Bureau of Justice Statistics, U.S. Department of Justice.

Roizen, Ron, William Kerr, and Kaye Fillmore. (1999). "Cirrhosis mortality and per capita consumption of distilled spirits, United States, 1949-94: trend analysis.” BMJ, 319(7211): 666-670.

Russell, Jenna. (2003). “Sunday Liquor Sale Ban to End.” Boston Globe, November 23.

Severson, Kim. (2011). “States Putting Hopes in 'Bottoms Up’ to Help the Bottom Line.” The New York Times. September 28, 2011. Page A1. 
Smart, R.G. (1977) "The relationship of availability of alcoholic beverages to per capita consumption and alcoholism rates.” Journal of Studies on Alcohol, 38:891-896.

Smith, D. Ian. (1990). "Effect on Casualty Traffic Accidents of Changing Sunday Alcohol Sales Legislation in Victoria, Australia.” Journal of Drug Issues, 20: 417-426.

Stehr, Mark. (2007). "The Effect of Sunday Sales Bans and Excise Taxes on Drinking and CrossBorder Shopping for Alcoholic Beverages.” National Tax Journal. Vol. 60, No. 1, pp. 85-106.

Stehr, Mark F. (2010) "The Effect of Sunday Sales of Alcohol on Highway Crash Fatalities," The B.E. Journal of Economic Analysis \& Policy: Vol. 10: Iss. 1 (Topics), Article 73.

Thaler, Richard, and Shlomo Benartzi (2004). "Save More Tomorrow: Using Behavioral Economics to Increase Employee Saving.” Journal of Political Economy, 112:S164-S187.

Zegler, Jennifer (2012), Dark Spirits - US - September 2012. Mintel Group Ltd.

Zegler, Jennifer (2013), Alcohol Consumption at Home - US - May 2013. Mintel Group Ltd. 
Table 1: Changes in Hours of Sale

\begin{tabular}{|c|c|c|c|c|}
\hline State & Year & On- or Off-Premises & Original Hours & New Hours \\
\hline Arizona & 1986 & Both & 13 & 15 \\
\hline Arizona & 2004 & Both & 15 & 16 \\
\hline Arkansas & 1999 & Both & 0 & 10 \\
\hline Colorado & 1997 & On & 12 & 19 \\
\hline Connecticut & 1993 & On & 0 & 15 \\
\hline District of Columbia & 2004 & On & 17 & 16 \\
\hline Florida & 1972 & Both & 0 & 17 \\
\hline Indiana & 2004 & On & 0 & 10 \\
\hline Iowa & 1974 & Both & 0 & 10 \\
\hline Iowa & 1984 & Both & 10 & 14 \\
\hline Iowa & 1991 & Both & 14 & 18 \\
\hline Kansas & 1986 & On & 0 & 17 \\
\hline Maine & 1976 & On & 0 & 13 \\
\hline Maine & 1991 & Off & 0 & 5 \\
\hline Maine & 1993 & Off & 5 & 13 \\
\hline Maine & 1995 & Both & 13 & 16 \\
\hline Massachusetts & 2004 & Off & 0 & 12 \\
\hline Massachusetts & 2004 & On & 0 & 13 \\
\hline Michigan & 1976 & Both & 10 & 12 \\
\hline Michigan & 2004 & Both & 12 & 14 \\
\hline Missouri & 1986 & On & 0 & 12 \\
\hline Missouri & 1993 & Off & 0 & 11 \\
\hline Missouri & 1993 & On & 12 & 13 \\
\hline Missouri & 1994 & Off & 11 & 13 \\
\hline Missouri & 2001 & Both & 13 & 15 \\
\hline Missouri & 2004 & Both & 15 & 19.5 \\
\hline Montana & 1975 & Both & 13 & 18 \\
\hline Nebraska & 1991 & Both & 0 & 13 \\
\hline New Hampshire & 1994 & Off & 14.75 & 17.75 \\
\hline New Hampshire & 1994 & On & 16 & 19 \\
\hline New Mexico & 1995 & Off & 0 & 12 \\
\hline New York & 1976 & On & 14 & 16 \\
\hline North Carolina & 1971 & On & 10.75 & 13 \\
\hline North Carolina & 1993 & On & 13 & 14 \\
\hline North Dakota & 1993 & Both & 0 & 13 \\
\hline North Dakota & 2004 & Both & 13 & 14 \\
\hline Ohio & 2001 & On & 11 & 14 \\
\hline Oregon & 2002 & Off & 0 & 15 \\
\hline Pennsylvania & 1975 & On & 9 & 13 \\
\hline Pennsylvania & 1984 & On & 13 & 15 \\
\hline Pennsylvania & 2002 & Off & 0 & 5 \\
\hline Rhode Island & 2004 & Off & 0 & 6 \\
\hline South Dakota & 1989 & Off & 0 & 17 \\
\hline South Dakota & 1991 & On & 11 & 13 \\
\hline South Dakota & 2004 & On & 13 & 15 \\
\hline Texas & 1993 & On & 12 & 14 \\
\hline Utah & 1985 & On & 12 & 11 \\
\hline Utah & 1993 & On & 11 & 12 \\
\hline Utah & 2004 & On & 12 & 15 \\
\hline Vermont & 1973 & Off & 9 & 14 \\
\hline Vermont & 2001 & Off & 14 & 18 \\
\hline Vermont & 2001 & On & 16 & 18 \\
\hline Virginia & 2004 & Off & 0 & 11 \\
\hline Washington & 1976 & On & 12 & 20 \\
\hline West Virginia & 1983 & On & 0 & 11 \\
\hline West Virginia & 1986 & On & 11 & 13 \\
\hline West Virginia & 2004 & On & 13 & 14 \\
\hline Wisconsin & 1988 & On & 17.5 & 20 \\
\hline Wyoming & 1973 & Both & 7 & 10 \\
\hline Wyoming & 1996 & Both & 10 & 20 \\
\hline
\end{tabular}


Table 2: Variable Definitions and Summary Statistics

\begin{tabular}{|c|c|c|c|}
\hline Variable & Description & Mean & $\begin{array}{l}\text { Standard } \\
\text { Deviation }\end{array}$ \\
\hline Sales & Per-capita distilled spirits sale(gallons of ethanol equivalent) & 0.972 & 0.472 \\
\hline LogSales & Log of ethanol-equivalent sales & -0.111 & 0.384 \\
\hline AllowSundayOnPremises & 1 if the state allows on-premises Sunday sales & 0.657 & 0.475 \\
\hline AllowSundayOffPremises & 1 if the state allows off-premises Sunday sales & 0.334 & 0.468 \\
\hline SundayOnHours & Number of on-premises Sunday sales hours & 10.0 & 7.70 \\
\hline SundayOffHours & Number of off-premises Sunday sales hours & 4.89 & 7.25 \\
\hline UnemploymentRate & State-level unemployment rate & 5.88 & 2.01 \\
\hline PopOver18 & State population over 18 years of age in millions & 3.69 & 4.16 \\
\hline LegalAge18 & 1 if the state drinking age is 18 in that year. & 0.083 & 0.272 \\
\hline LegalAge19 & 1 if the state drinking age is 19 in that year. & 0.076 & 0.258 \\
\hline LegalAge20 & 1 if the state drinking age is 20 in that year. & 0.031 & 0.162 \\
\hline LegalAge21 & 1 if the state drinking age is 21 in that year. & 0.811 & 0.389 \\
\hline Expand & Local option to expand on- or off-premises Sunday hours from the default. & 0.501 & 0.500 \\
\hline Restrict & Local option to restrict on- or off-premises Sunday hours from the default. & 0.426 & 0.496 \\
\hline OnInflows & $\begin{array}{l}\text { Number of on-premises sale hours in excess of neighbor states, weighted } \\
\text { by neighbor state border county population over own state population }\end{array}$ & 2.66 & 7.74 \\
\hline OffInflows & $\begin{array}{l}\text { Number of off-premises sale hours in excess of neighbor states, weighted } \\
\text { by neighbor state border county population over own state population }\end{array}$ & 2.08 & 7.05 \\
\hline OnOutflows & $\begin{array}{l}\text { Number of on-premises sale hours less than neighbor states, weighted by } \\
\text { own state border county population over own state population }\end{array}$ & 3.21 & 7.59 \\
\hline OffOutflows & $\begin{array}{l}\text { Number of off-premises sale hours less than neighbor states, weighted by } \\
\text { own state border county population over own state population }\end{array}$ & 2.71 & 6.06 \\
\hline
\end{tabular}

This table reports means and standard deviations for 1722 observations across 47 states that had a state default for both on- and off-premises hours of sale for at least one year. 
Table 3: Main Results

\begin{tabular}{|c|c|c|c|c|}
\hline Variable & (1) & (2) & (3) & (4) \\
\hline SundayOnHours & $\begin{array}{c}0.0094 * * * \\
(0.0029)\end{array}$ & $\begin{array}{l}0.0116 * * \\
(0.0035)\end{array}$ & $\begin{array}{c}0.0093^{* * *} \\
(0.0029)\end{array}$ & $\begin{array}{c}0.0099 * * * \\
(0.0032)\end{array}$ \\
\hline SundayOffHours & $\begin{array}{c}0.0008 \\
(0.0024)\end{array}$ & $\begin{array}{c}0.0012 \\
(0.0025)\end{array}$ & $\begin{array}{l}-0.0051 \\
(0.0049)\end{array}$ & $\begin{array}{l}-0.0011 \\
(0.0026)\end{array}$ \\
\hline SundayOnHours x SundayOffHours & - & - & $\begin{array}{c}0.0004 \\
(0.0003)\end{array}$ & - \\
\hline NonSundayAverageOnHours & - & - & - & $\begin{array}{l}-0.0033 \\
(0.0058)\end{array}$ \\
\hline NonSundayAverageOffHours & - & - & - & $\begin{array}{l}-0.0107 \\
(0.0071)\end{array}$ \\
\hline $\begin{array}{c}\text { Liquor Tax } \\
\text { (log of real dollars per gallon) }\end{array}$ & $\begin{array}{c}-0.0321^{* *} \\
(0.0152)\end{array}$ & - & $\begin{array}{c}-0.0508 * * \\
(0.0229)\end{array}$ & $\begin{array}{l}-0.0293^{*} \\
(0.0157)\end{array}$ \\
\hline $\begin{array}{c}\text { Cigarette Tax } \\
\text { (log of real dollars per pack) }\end{array}$ & $\begin{array}{c}-0.0278^{* *} \\
(0.0125)\end{array}$ & - & $\begin{array}{c}-0.0281^{* *} \\
(0.0122)\end{array}$ & $\begin{array}{l}-0.0235^{*} \\
(0.0131)\end{array}$ \\
\hline LegalAge18 & $\begin{array}{c}0.0700 \\
(0.0743)\end{array}$ & $\begin{array}{c}0.0482 \\
(0.0397)\end{array}$ & $\begin{array}{c}0.0754 \\
(0.0716)\end{array}$ & $\begin{array}{c}0.0473 \\
(0.0818)\end{array}$ \\
\hline LegalAge19 & $\begin{array}{l}-0.0346 \\
(0.0204)\end{array}$ & $\begin{array}{l}-0.0057 \\
(0.0235)\end{array}$ & $\begin{array}{l}-0.0290 \\
(0.0209)\end{array}$ & $\begin{array}{l}-0.0378^{*} \\
(0.0220)\end{array}$ \\
\hline LegalAge20 & $\begin{array}{l}-0.0185 \\
(0.0219)\end{array}$ & $\begin{array}{l}-0.0381 \\
(0.0226)\end{array}$ & $\begin{array}{l}-0.0152 \\
(0.0225)\end{array}$ & $\begin{array}{l}-0.0324 \\
(0.0253)\end{array}$ \\
\hline Expand & $\begin{array}{c}0.0120 \\
(0.0203)\end{array}$ & $\begin{array}{l}0.0483 * * \\
(0.0218)\end{array}$ & $\begin{array}{c}0.0083 \\
(0.0200)\end{array}$ & $\begin{array}{c}0.0096 \\
(0.0194)\end{array}$ \\
\hline Restrict & $\begin{array}{c}-0.0458^{* *} \\
(0.0231)\end{array}$ & $\begin{array}{l}-0.0640 * * \\
(0.0232)\end{array}$ & $\begin{array}{l}-0.0393 \\
(0.0242)\end{array}$ & $\begin{array}{l}-0.0334 \\
(0.0216)\end{array}$ \\
\hline $\mathrm{N}$ & 1196 & 1722 & 1196 & 1050 \\
\hline
\end{tabular}

Coefficients are reported for OLS models with the log of per-capita alcohol sales as the dependent variable. Each regression also includes state and year fixed effects, controls for restrictions on liquor sales hours in neighboring states, the state's unemployment rate, and the state's total population. Standard errors clustered at the state level are in parentheses; those significant at the $10 \%$ level are marked with * and those significant at the $5 \%$ level are marked with **. Column (1) is our basic specification. Column (2) drops the liquor tax and cigarette tax variables in order to expand the sample. Column (3) adds a interaction between allowable on-premises and off-premises hours to the basic specification in order to investigate a possibility described in Section 3.3. Column (4) supplements the basic specification with measures of allowable alcohol sales hours on days other than Sunday. 
Table 4: Tests of the Identifying Assumptions

\begin{tabular}{|c|c|c|c|c|}
\hline Variable & (1) & (2) & (3) & (4) \\
\hline SundayOnHours & $\begin{array}{c}0.0077 * * * \\
(0.0025)\end{array}$ & $\begin{array}{c}0.0071^{* * *} \\
(0.0023)\end{array}$ & $\begin{array}{c}0.0066^{* *} \\
(0.0027)\end{array}$ & $\begin{array}{c}0.0087^{* * *} * \\
(0.0029)\end{array}$ \\
\hline SundayOffHours & $\begin{array}{c}0.0002 \\
(0.0026)\end{array}$ & $\begin{array}{c}0.0008 \\
(0.0025)\end{array}$ & $\begin{array}{c}-0.0004 \\
(0.0024)\end{array}$ & $\begin{array}{c}0.0009 \\
(0.0030)\end{array}$ \\
\hline SundayOnHours - Lead & $\begin{array}{c}0.0014 \\
(0.0017)\end{array}$ & $\begin{array}{l}-0.0010 \\
(0.0025)\end{array}$ & - & - \\
\hline SundayOffHours - Lead & $\begin{array}{c}0.0009 \\
(0.0019)\end{array}$ & $\begin{array}{l}-0.0010 \\
(0.0021)\end{array}$ & - & - \\
\hline SundayOnHours - Two Leads & - & $\begin{array}{c}0.0029 \\
(0.0031)\end{array}$ & - & - \\
\hline SundayOffHours - Two Leads & - & $\begin{array}{c}0.0019 \\
(0.0027)\end{array}$ & - & - \\
\hline SundayOnHours - Lag & - & - & $\begin{array}{c}-0.0003 \\
(0.0009)\end{array}$ & - \\
\hline SundayOffHours - Lag & - & - & $\begin{array}{c}-0.0004 \\
(0.0011)\end{array}$ & - \\
\hline SundayOnHours - Two Lags & - & - & $\begin{array}{c}0.0018 \\
(0.0021)\end{array}$ & - \\
\hline SundayOffHours - Two Lags & - & - & $\begin{array}{c}0.0020 \\
(0.0018)\end{array}$ & - \\
\hline EverOnChange $\mathrm{x}$ Trend & - & - & - & $\begin{array}{c}0.0011 \\
(0.0019)\end{array}$ \\
\hline EverOffChange $x$ Trend & - & - & - & $\begin{array}{c}0.0011 \\
(0.0021)\end{array}$ \\
\hline $\mathrm{N}$ & 1149 & 1102 & 1104 & 1196 \\
\hline
\end{tabular}

Coefficients are reported from OLS models with the log of per-capita alcohol sales as the dependent variable. Each regression also includes a set of indicators for the state's legal drinking age, indicators for whether local jurisdictions can expand or restrict hours of sale, unemployment rate, population, neighboring state controls, the log of liquor and cigarette taxes, and state and year fixed effects. Standard errors clustered at the state level are in parentheses; those significant at the $10 \%$ level are marked with * and those significant at the $5 \%$ level are marked with **. Column (1) supplements the basic specification with leads for the key policy variables; column (2) adds a second lead. Column (3) supplements the basic specification with two lags. Column (4) adds separate trends for states that did and did not change their Sunday restrictions during the sample period. 
Table 5: Additional Robustness Checks

\begin{tabular}{|c|c|c|c|c|}
\hline Variable & (1) & (2) & (3) & (4) \\
\hline SundayOnHours & $\begin{array}{c}0.0095^{* * *} \\
(0.0028)\end{array}$ & $\begin{array}{c}0.0095^{* * *} \\
(0.0028)\end{array}$ & $\begin{array}{c}0.0089 * * * \\
(0.0028)\end{array}$ & - \\
\hline SundayOffHours & $\begin{array}{c}0.0008 \\
(0.0024)\end{array}$ & $\begin{array}{c}0.0008 \\
(0.0023)\end{array}$ & $\begin{array}{c}0.0003 \\
(0.0024)\end{array}$ & - \\
\hline AllowsSundayOn & - & - & - & $\begin{array}{r}0.0805^{* *} \\
(0.0366)\end{array}$ \\
\hline AllowsSundayOff & - & - & - & $\begin{array}{c}0.0367 \\
(0.0297)\end{array}$ \\
\hline Ban on Smoking in Bars & $\begin{array}{c}0.0038 \\
(0.0259)\end{array}$ & - & - & - \\
\hline $\begin{array}{c}\text { Wine Tax } \\
\text { (log of real dollars per gallon) }\end{array}$ & - & $\begin{array}{c}0.0032 \\
(0.0200)\end{array}$ & - & - \\
\hline $\begin{array}{c}\text { Beer Tax } \\
\text { (log of real dollars per gallon) }\end{array}$ & - & $\begin{array}{c}0.0595 \\
(0.0738)\end{array}$ & - & - \\
\hline Log of Beer Consumption & - & - & $\begin{array}{l}0.324 * * * \\
(0.0890)\end{array}$ & - \\
\hline Log of Wine Consumption & - & - & $\begin{array}{l}0.104 * * \\
(0.0397)\end{array}$ & - \\
\hline $\mathrm{N}$ & 1196 & 1196 & 1196 & 1196 \\
\hline
\end{tabular}

Coefficients are reported from OLS models with the log of per-capita alcohol sales as the dependent variable. Each regression also includes a set of indicators for the state's legal drinking age, indicators for whether local jurisdictions can expand or restrict hours of sale, unemployment rate, population, neighboring state controls, the log of liquor and cigarette taxes, and state and year fixed effects. Standard errors clustered at the state level are in parentheses; those significant at the $10 \%$ level are marked with * and those significant at the $5 \%$ level are marked with **. Columns (1) through (3) supplement the basic specification with variables measuring, respectively, whether smoking was allowed in bars, the tax rates on wine and beer, and the total amount of beer and wine consumption. Column (4) replaces our measures of allowable Sunday sales hours with dichotomous variables indicating whether any Sunday sales were permitted. 